\title{
Molybdenum Cofactor and Sulfite Oxidase Deficiency
}

\section{Jochen Reiss*}

Institute of Human Genetics, University Medicine Göttingen, Germany

\begin{abstract}
A universal molybdenum-containing cofactor is necessary for the activity of all eukaryotic molybdoenzymes. In humans four such enzymes are known: Sulfite oxidase, xanthine oxidoreductase, aldehyde oxidase and a mitochondrial amidoxime reducing component. Of these, sulfite oxidase is the most important and clinically relevant one. Mutations in the genes MOCS1, MOCS2 or GPHN - all encoding cofactor biosynthesis proteins - lead to molybdenum cofactor deficiency type A, B or C, respectively. All three types plus mutations in the SUOX gene responsible for isolated sulfite oxidase deficiency lead to progressive neurological disease which untreated in most cases leads to death in early childhood. Currently, only for type A of the cofactor deficiency an experimental treatment is available.
\end{abstract}

\section{Introduction}

Isolated sulfite oxidase deficiency (MIM\#606887) is an autosomal recessive inherited disease caused by mutations in the sulfite oxidase (SUOX) gene [1]. Sulfite oxidase is localized in the mitochondrial intermembrane space, where it catalyzes the oxidation of sulfite to sulfate as a homodimer. Lack of this enzyme activity results in elevated sulfite levels, which subsequently cause severe neurological symptoms including untreatable seizures and progressive neurodegeneration. In the absence of effective treatment options, death typically occurs at an early stage although milder cases have been described.

More often a so called combined form of sulfite oxidase deficiency is found, which is caused by the absence of a molybdenum containing cofactor required for the activity of sulfite oxidase deficiency and additionally that of xanthine oxidoreductase, aldehyde oxidase and a mitochondrial amidoxime reducing component [2]. This combined form is also inherited autosomal recessively and caused by mutations in the genes MOCS1 (MIM\#603707), MOCS2 (MIM\#603708) or GPHN (MIM\#603930). Clinically, this combined form of the disease is identical to the before described isolated form. However, the two forms can be distinguished biochemically by absence or presence of xanthine oxidoreductase activity. In the combined form, an increased level of xanthine and a reduced level of uric acid are found.

\section{Apoenzymes of the Molybdenum Cofactor}

\section{Sulfite oxidase}

A common cofactor for oxidoreductases was postulated as early as in 1964 and a few years later sulfite oxidase was added to the short list of mammalian enzymes containing molybdenum besides xanthine oxidase and aldehyde oxidase [3,4]. Indeed, all eukaryotic molybdoenzymes contain the molybdenum in the form of a molybdenum cofactor (MoCo). This cofactor contains a universal prosthetic group called molybdopterin, which binds and coordinates the catalytically active molybdenum within the holoenzyme [5]. For humans, sulfite oxidase (SUOX) is the most important MoCo-dependant enzyme. So far, 25 different mutations causing isolated SUOX deficiency have been described and are listed in Table 1. Recently, hyperekplexia has been described as an additional consequence of homozygous SUOX mutations [6].

\section{Xanthine oxidoreductase}

Classical xanthinuria (type I) is caused by mutations in the gene for xanthine oxidoreductase (XOR) and reflects an isolated XOR deficiency [7]. In MoCo deficiency, XOR deficiency is seen in combination with SUOX deficiency. Elevated xanthine and lowered uric acid concentrations in the urine are used to differentiate this combined form from the isolated SUOX deficiency. Rarely and only in cases of isolated XOR deficiency xanthine stones have been described as a cause of renal failure. Otherwise, isolated XOR deficiency often goes unnoticed. There is, however, a large body of evidence, that XOR has an additional and merely structural role during secretion of milk droplets in the lactating mammary gland [8-10].

\section{Aldehyde oxidase}

The MoCo-dependent human aldehyde oxidase (AOX1) has a broad substrate specificity partially overlapping with that of other enzymes, e.g. the above listed XOR. A number of polymorphisms in the AOX1 gene are known, which influence the catalytic activity, but no case of isolated AOX1 deficiency has been described. A heterozygous de novo mutation has been reported in a schizophrenia patient, but since no functional analysis was done, this could be a non-pathogenic variant [11]

\section{Mitochondrial amidoxime reducing component}

In 2006 a fourth MoCo-dependent enzyme activity was described, which together with cytochrome $b_{5}$ and its corresponding reductase catalyzes the reduction of $\mathrm{N}$-hydroxylated compounds such as amidoximes at the outer mitochondrial membrane [12]. Apparently, all mammals express two isoforms encoded by the genes MARC 1 and MARC2, which are also referred to as MOSC1 and MOSC2 [13,14]. Functional polymorphisms have been described for MARC2, but none of the two genes has been held responsible for a specific disease to date.

\section{Molybdenum Cofactor Biosynthesis Genes MOCS1}

The MOCS1 gene was the first human gene identified in the conserved pathway (Figure 1) leading from GTP to active MoCo [15].

*Corresponding author: Jochen Reiss, Institute of Human Genetics, University Medicine Göttingen, Germany, Tel: 495513912926; E-mail: mailto:jreiss@gwdg.de

Received August 04, 2016; Accepted August 31, 2016; Published September 05, 2016

Citation: Reiss J (2016) Molybdenum Cofactor and Sulfite Oxidase Deficiency Metabolomics (Los Angel) 6: 184. doi: 10.4172/2153-0769.1000184

Copyright: ( 2016 Reiss J, et al. This is an open-access article distributed under the terms of the Creative Commons Attribution License, which permits unrestricted use, distribution, and reproduction in any medium, provided the original author and source are credited. 


\section{Guanosine Triphosphate (GTP)}
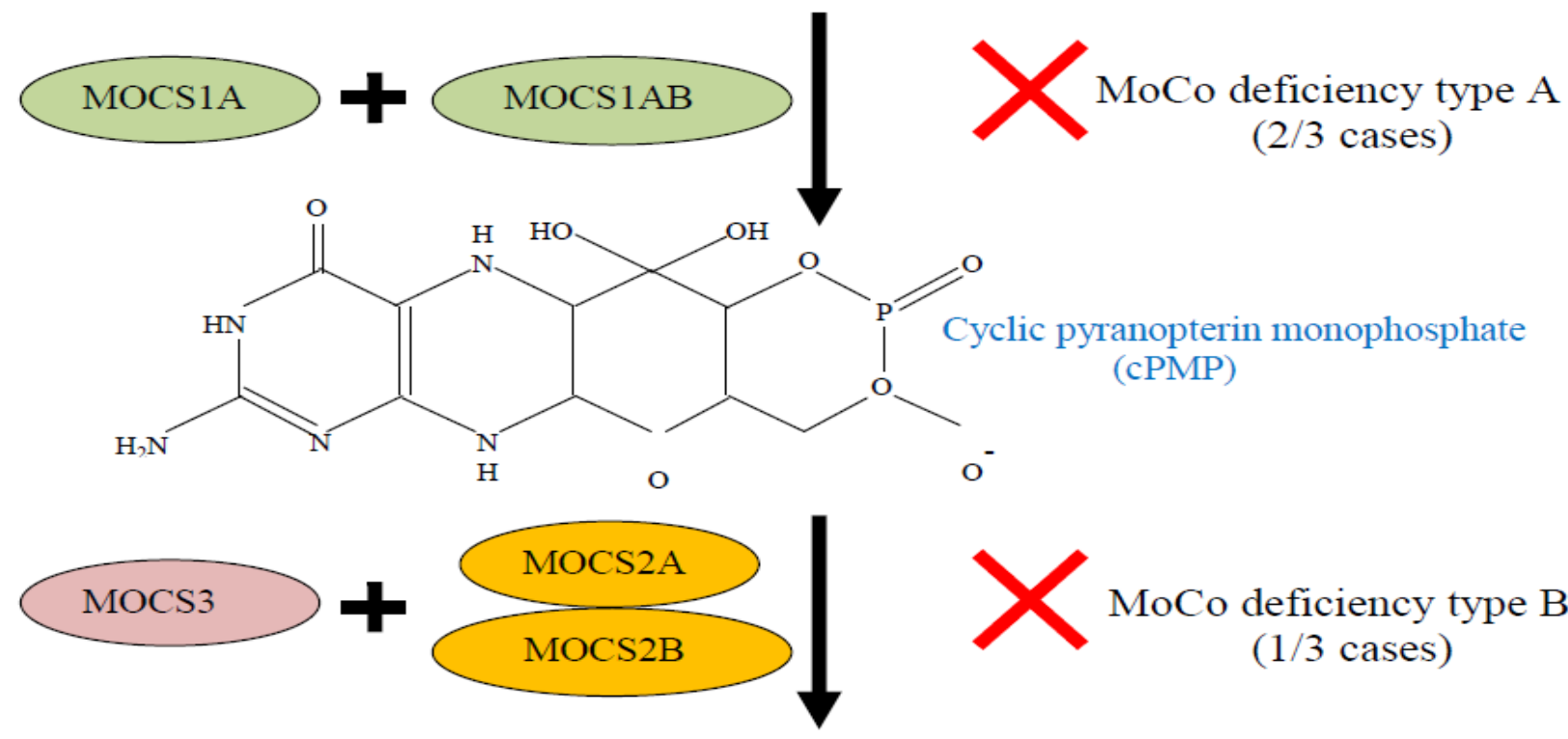

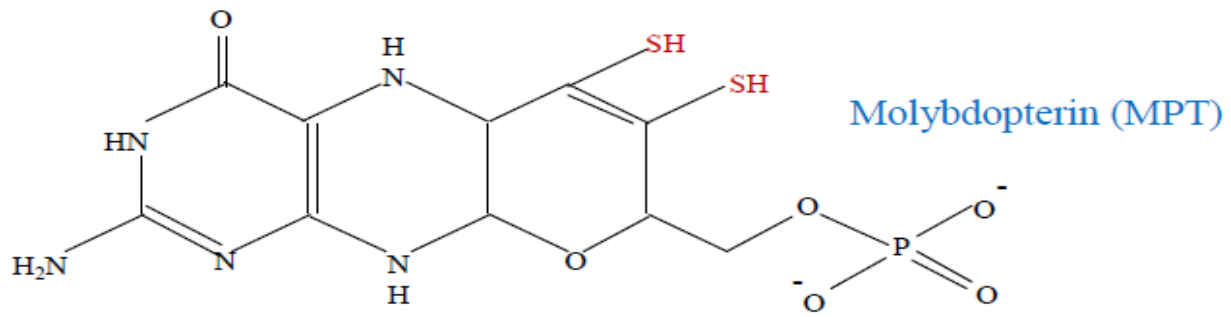
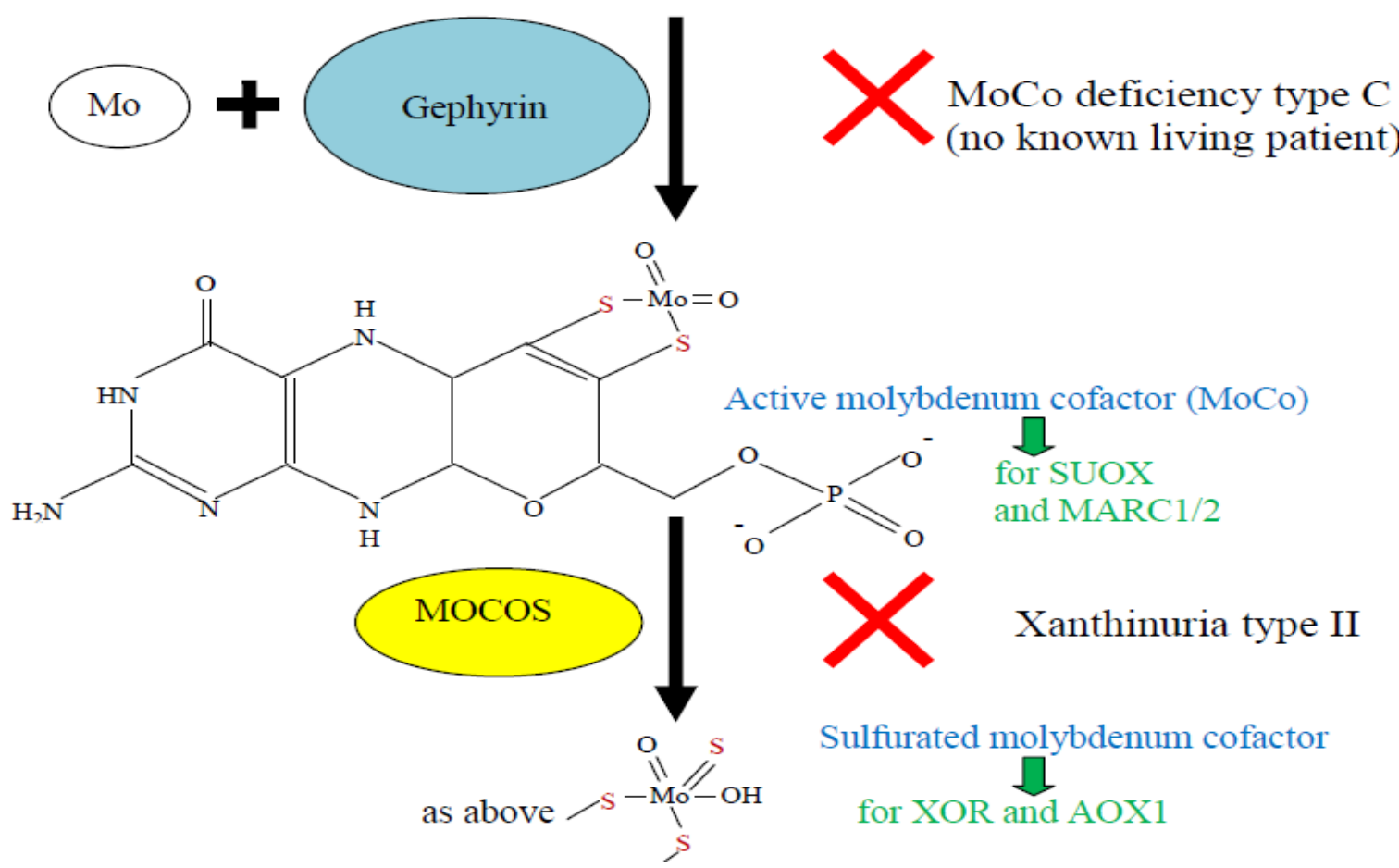

Figure 1: Biosynthesis of the molybdenum cofactor. Involved proteins are depicted on the left and the corresponding inherited diseases on the right. 
Two consecutive open reading frames (ORF) A and B are found on the full length cDNA, which correspond to different genes in bacteria and plants [2]. ORF A is expressed via this full length cDNA leading to the protein MOCS1A, which carries a double glycin at the C-terminus essential for its catalytic function. Alternative splicing-involving exon 9 of a total of 10 exons-omits this motif and the corresponding stop codon. This leads to a fusion protein MOCS1AB, which consists of a nearly complete $\mathrm{A}$ domain and an additional $\mathrm{B}$ domain encoded by the second ORF. Both MOCS1A and MOCS1AB are necessary for the formation of cyclic pyranopterin monophosphate (cPMP) formerly described as precursor $\mathrm{Z}$, which is the first and a relatively stable intermediate of the MoCo pathway [16].

Approximately two thirds of all MoCo-deficient patients are homozygous or compound heterozygous for mutations in the MOCS1 gene. In Table 2 all mutations described as responsible for MoCo deficiency are summarized. The two mutations in the compound heterozygotes are always located in the same domain, which indirectly demonstrates intragenic complementation if different domains are affected [2]. Complementation can also be seen during cocultivation of fibroblasts derived from different patients [17]. Cells unable to further process cPMP accumulate and excrete this intermediate, which is taken up and transformed to active MoCo by other cells which have their block in the first step leading to cPMP. Accordingly, the patients originally were divided into type A with MOCS1 mutations and type $\mathrm{B}$ with mutations in any of the other MoCo biosynthesis genes. In a patient combining all criteria for MoCo deficiency with a pronounced neonatal hyperekplexia only one mutation in the MOCS1 gene was identified despite extensive sequence analysis of all genes in question [18]. Since the heterozygous parents of affected patients are known to be devoid of any disease typical symptoms, it can be speculated that here a second pathogenic mutation was located either deep in an intron (leading to the activation of a cryptic splice site) or in a promoter or regulator sequence adjunct to the gene.

\section{MOCS2}

Nearly all of the remaining cases, i.e., approximately one third of the patients, carry homozygous or compound heterozygous mutations in the MOCS2 gene [2]. MOCS2 also encodes two different proteins, but the corresponding ORFs overlap in exon 3 of a total of 7 exons with the downstream ORF being shifted by one nucleotide with regard to the upstream ORF. Here, alternative first exons (named exon 1a and exon $1 \mathrm{~b}$ ) fuse to exon 2 of the MOCS2 gene and thus lead to the two proteins MOCS2A and MOCS2B.

MOCS2A is the small subunit and MOCS2B the large subunit of the heterodimeric molybdopterin synthase, which in turn dimerizes to form a heterotetramer [19]. As MOCS1A, MOCS2 A carries a conserved double glycin at its C-terminus. Molybdopterin synthase introduces two sulfhydryl groups into cPMP, which finally will hold the catalytic metal ion in place. Due to these sulfur groups, molybdopterin as well as active MoCo are extremely unstable when exposed to oxygen [20]. Recently, molybdopterin synthase has been shown to take part in the regulation of RNA activated protein kinase (PKR) which in turn regulates apoptosis [21,22].

\section{MOCS3}

The small subunit of molybdopterin synthase (MOCS2A) must be sulfurated by MOCS3, the gene product of the intronless MOCS3 gene. No disease-causing mutation responsible for MoCo deficiency or any other disease has been described within this gene (HGMD, 2016). With regard to MoCo biosynthesis one should clearly expect the phenotype

\begin{tabular}{|c|c|c|}
\hline Nucleotide change & Predicted effect & Reference \\
\hline c. $182 \mathrm{~T}>\mathrm{C}$ & p.L61P & [48] \\
\hline c.287dupC & Frame shift & [1] \\
\hline c.520delG & Frame shift & [49] \\
\hline c.571delC & Frame shift & {$[50]$} \\
\hline c.571_574delCAGC & Frame shift & [1] \\
\hline c. $623 \mathrm{C}>\mathrm{A}$ & p.A208D & [51] \\
\hline c. $650 \mathrm{G}>\mathrm{A}$ & p.R217Q & [52] \\
\hline c.734_737delTTTC & Frame shift & [1] \\
\hline c. $772 \mathrm{~A}>\mathrm{C}$ & p.I258L & [1] \\
\hline c. $794 \mathrm{C}>\mathrm{A}$ & p.A265D & [52] \\
\hline c. $803 \mathrm{G}>\mathrm{A}$ & p.R268Q & [1] \\
\hline c. $1084 G>A$ & p.G362S & [1] \\
\hline c. $1097 \mathrm{G}>\mathrm{A}$ & p.R366H & [1] \\
\hline c. $1109 \mathrm{C}>\mathrm{A}$ & p.S370Y & [51] \\
\hline c. $1126 \mathrm{C}>\mathrm{T}$ & p.R376C & [1] \\
\hline c. $1136 A>G$ & p.K379R & [1] \\
\hline c. $1187 A>G$ & p.Q396R & [1] \\
\hline c. $1200 C>G$ & p.Y400X & [1] \\
\hline c.1234_1235delGT & Frame shift & [53] \\
\hline c. $1261 \mathrm{C}>\mathrm{T}$ & p.Q421X & [1] \\
\hline c.1313_1316delTAGA & Frame shift & [54] \\
\hline c. $1348 \mathrm{~T}>\mathrm{C}$ & p.W450R & [1] \\
\hline c. $1355 \mathrm{G}>\mathrm{A}$ & p.G452D & [55] \\
\hline c.1521_1524delTTGT & Frame shift & [1] \\
\hline c. $1589 G>A$ & p.G530D & {$[52]$} \\
\hline
\end{tabular}

Table 1: Mutations in the SUOX gene responsible for isolated sulfite oxidase deficiency as known in August 2016.

of a MoCo deficiency type B as the activity of molybdopterin synthase strictly depends on MOCS3 activity [23]. Since MOCS3 activity is also involved in tRNA thiolation and thereby in global processes like nuclear transport, cytokinesis and cell cycle progression one might, however, also speculate on a possible embryonal lethality as a consequence of hitherto not described MOCS3 mutations [24].

\section{GPHN}

The protein gephyrin was originally described for its function in glycine receptor clustering [25]. Sequence homologies to bacterial, insect and plant genes suggested an additional role in the insertion of molybdenum into the cofactor [26,27]. This was confirmed by the phenotype of gephyrin-deficient knockout mice, which also suggested gephyrin mutations to be responsible for hyperekplexia [28]. In a MoCodeficient patient with hyperreflexia a homozygous frame shift mutation in the GPHN gene was identified, which abolished protein translation after exon 1 of a total of 27 exons [29]. This mutation abolishes the $\mathrm{N}$-terminal "G domain" as well as the C-terminal "E domain" (being named after their homologous bacterial gene). In fibroblast cultures derived from this patient, MoCo synthesis and activity could be restored by high concentrations of inorganic molybdate. Although this type $\mathrm{C}$ of MoCo deficiency appears to be curable by these means, transgenic mice carrying the plant homologue $\mathrm{Cnxl}$ on a gephyrin-deficient background despite restored MoCo activity showed unchanged early lethality due to the absence of receptor clustering [30]. One MoCodeficient patient with a homozygous point mutation in the $\mathrm{E}$ domain of gephyrin was also described [31]. In contrast to the above case, fibroblasts from the latter patient could not be restored by inorganic molybdate. The still active $\mathrm{G}$ domain here adenylates molybdopterin, while an inactive $\mathrm{E}$ domain prohibits deadenylation and blocks nonenzymatic molybdenum insertion. Consequently, patients with 


\begin{tabular}{|c|c|c|c|}
\hline Gene & Nucleotide change & Predicted effect & Reference \\
\hline MOCS1 & c.99_100delGG & Frameshift & [2] \\
\hline MOCS1 & c.195_212del18 & p.G66_Y71del & [56] \\
\hline MOCS1 & c.199C>T & p.R67W & [57] \\
\hline MOCS1 & $c .217 \mathrm{C}>\mathrm{T}$ & p.R73W & [56] \\
\hline MOCS1 & c. $218 \mathrm{G}>\mathrm{A}$ & p.R73Q & [2] \\
\hline MOCS1 & c. $238 \mathrm{~T}>\mathrm{G}$ & p.C80G & [57] \\
\hline MOCS1 & c. $250 \mathrm{~T}>\mathrm{C}$ & p.C84R & [2] \\
\hline MOCS1 & c. $251 \mathrm{G}>\mathrm{T}$ & p.C84F & [57] \\
\hline MOCS1 & c. $253 C>T$ & p.Q85X & [2] \\
\hline MOCS1 & c. $256 \mathrm{~T}>\mathrm{G}$ & p.Y86D & [2] \\
\hline MOCS1 & c.269_270delAG & Frameshift & [58] \\
\hline MOCS1 & c.291delC & Frameshift & [59] \\
\hline MOCS1 & c. $367 \mathrm{C}>\mathrm{T}$ & p.R123W & [59] \\
\hline MOCS1 & c. $377 \mathrm{G}>\mathrm{A}$ & p.G126D & [56] \\
\hline MOCS1 & c. $379 \mathrm{G}>\mathrm{A}$ & p.G127R & [56] \\
\hline MOCS1 & $c .394 \mathrm{C}>\mathrm{T}$ & p.R132W & [2] \\
\hline MOCS1 & c. $418+1 \mathrm{G}>\mathrm{A}$ & Skipping exon 2 & [56] \\
\hline MOCS1 & c. $583+1 \mathrm{G}>\mathrm{A}$ & Skipping exon 3 & [57] \\
\hline MOCS1 & c.603_623del21 & p.G202_E208del & [2] \\
\hline MOCS1 & c. $664 \mathrm{C}>\mathrm{T}$ & p.R222X & [2] \\
\hline MOCS1 & c.666_667insCGA & R222_G223insR & [57] \\
\hline MOCS1 & c.721delC & Frameshift & [2] \\
\hline MOCS1 & c.722delT & Frameshift & [15] \\
\hline MOCS1 & c. $956 \mathrm{G}>\mathrm{A}$ & p.R319Q & [56] \\
\hline MOCS1 & c. $970 \mathrm{G}>\mathrm{A}$ & p.G324R & [59] \\
\hline MOCS1 & c. $971 \mathrm{G}>\mathrm{A}$ & p.G324E & [56] \\
\hline MOCS1 & c.1000insT & Frameshift & [2] \\
\hline MOCS1 & c.1015_1018del4 & Frameshift & [57] \\
\hline MOCS1 & c. $1027 \mathrm{C}>\mathrm{T}$ & p.R343X & [57] \\
\hline MOCS1 & c. $1064 \mathrm{~T}>\mathrm{C}$ & p.1355T & [18] \\
\hline MOCS1 & c. $1102+1 G>A$ & Skipping exon 8 & [56] \\
\hline MOCS1 & c. $1150 \mathrm{G}>\mathrm{A}$ & p.G384S & [56] \\
\hline MOCS1 & c. $1165+6 T>C$ & Skipping exon 9 & [60] \\
\hline MOCS1 & c.1313_1314insG & Frameshift & [56] \\
\hline MOCS1 & c.1502_1507del6insCT & Frameshift & [2] \\
\hline MOCS1 & c.1523_1524del2 & Frameshift & [15] \\
\hline MOCS1 & c.1640delA & Frameshift & [2] \\
\hline MOCS1 & c. $1777 \mathrm{G}>\mathrm{A}$ & p.G588R & [57] \\
\hline MOCS1 & c. $1798 \mathrm{~A}>\mathrm{C}$ & p.T595P & [56] \\
\hline MOCS1 & c. $1826 \mathrm{~T}>\mathrm{C}$ & p.L604P & [2] \\
\hline MOCS1 & c.1838_1843del6insCC & Frameshift & [2] \\
\hline MOCS2 & c.-9_14del23 & Initiation failure & [61] \\
\hline MOCS2 & c. $1 A>G$ & Initiation failure & [2] \\
\hline MOCs2 & c. $3 \mathrm{G}>\mathrm{A}$ & Initiation failure & [62] \\
\hline MOCS2 & c. $16 \mathrm{C}>\mathrm{T}$ & p.Q6X & [63] \\
\hline MOCS2 & c. $19 \mathrm{G}>\mathrm{T}$ & p.V7F & [63] \\
\hline MOCs2 & c. $33 \mathrm{~T}>\mathrm{G}$ & p.Y11X & [57] \\
\hline MOCS2 & c. $45 \mathrm{~T}>\mathrm{A}$ & p.S15R & [59] \\
\hline MOCS2 & c. $88 \mathrm{C}>\mathrm{T}$ & p.Q30X & [59] \\
\hline MOCS2 & c. $106 \mathrm{C}>\mathrm{T}$ & p.Q36X & [59] \\
\hline MOCS2 & c. $130 \mathrm{C}>\mathrm{T}$ & p.R44X & [64] \\
\hline MOCS2 & c. $220 \mathrm{C}>\mathrm{T}$ & p.Q74X & [2] \\
\hline MOCS2 & c.252_253insC & Frameshift & [62] \\
\hline MOCS2 & c. $413 \mathrm{G}>\mathrm{A}$ & p.G76R & [59] \\
\hline MOCS2 & c.501delA & Frameshift & [2] \\
\hline MOCS2 & c.533_536del4 & Frameshift & [62] \\
\hline MOCS2 & c. $564 \mathrm{G}>\mathrm{C}$ & p.G126A & [59] \\
\hline MOCS2 & c. $564+1 \mathrm{G}>\mathrm{A}$ & Skipping exon 5 & [2] \\
\hline MOCS2 & c.635_637del3 & p.A150del & [59] \\
\hline MOCs2 & c.658_664del7insG & p.L158_K159del & [59] \\
\hline
\end{tabular}

\begin{tabular}{|c|c|c|c|}
\hline MOCS2 & c.689G $>$ A & p.E168K & {$[62]$} \\
\hline MOCS2 & c.714_718del5 & Frameshift & {$[59]$} \\
\hline MOCS2 & c.726_727delAA & Frameshift & {$[62]$} \\
\hline MOCS2 & c.754A $>$ C & Termination failure & {$[57]$} \\
\hline GPHN & c.65-?_102+?del & Frameshift & {$[29]$} \\
\hline GPHN & c.1838A $>$ C & p.D613A & {$[31]$} \\
\hline
\end{tabular}

Table 2: Mutations causative for combined MoCo deficiency in the genes MOCS1, MOCS2 and GPHN as known in August 2016.

isolated $\mathrm{E}$ domain mutations should be grouped in yet another type $\mathrm{D}$ of MoCo deficiency.

Various alternative splicing involves several facultative exon "cassettes" and leads to at least 11 different GPHN transcripts, which are believed to be more or less tissue-specific [32]. Further work along this line suggests that these isoforms reflect different gephyrin populations either involved in MoCo biosynthesis or fulfilling structural tasks in synapse receptor clustering [33]. In the brain of epilepsy patients without genomic GPHN mutations irregular splicing of GPHN RNA has been observed, which impairs $G$ domain-dependent oligomerization and has a dominant-negative effect by interacting with normally spliced gephyrin [34]. Since the same isoforms could be "environmentally" induced in cell cultures by cellular stress such as alkalosis, it is believed that seizure activity could be responsible for this observation. Interestingly, heterozygous gross deletions held responsible for autism, schizophrenia and seizures show a common overlap in the same region [35].

\section{MOCOS}

Before its incorporation into XOR or AOX1, but not into SUOX, the MoCo has to be sulfurated by an enzyme called MoCo Sulfurase (MOCOS alias MCSU) [7]. Mutations in the corresponding gene MOCOS abolish XOR and AOX1 activity resulting in xanthinuria type II, which can be distinguished from type I by presence or absence of the ability to convert allopurinol to oxipurinol [36]. Hitherto, five xanthinuria patients with MOCOS mutations have been described $[7,37]$. Due to a reduced expression level of MOCOS in olfactory stem cells of patients with autism spectrum disorders (ASD), the gene was also brought in context with neurodevelopment and neurotransmission [38].

\section{Animal Models and Experimental Therapies}

Murine disease models have been created by targeted gene disruption for Gphn and Mocs1 deficiency [28,29]. Homozygous Gephyrin-deficient mice do not survive their first day of life and the comparison with Mocs $1 /$ mice illustrates that this is caused by the loss of receptor clustering rather than the disturbance of MoCo biosynthesis.

Mocs1-deficient mice die within 14 days after birth and since they reflect the biochemical situation in most of the patients they have repeatedly been used for therapeutical studies.

The feasibility of a biochemical substitution therapy for MoCo deficiency type A using CPMP was demonstrated in these mice and later successfully transferred to human patients $[39,40]$.

AAV-mediated gene therapy of these animals also proved to be very successful in that a single injection of recombinant virus rescued the phenotype for years [41,42]. By now, a large body of evidence has accumulated that AAV applications can increase the risk for hepatocellular carcinoma (HCC), but also that this risk can be minimized by modulating several parameters such as vector dose or enhancer/promoter selection [43]. 
Recently, a murine model for MoCo deficiency type B was described, which essentially reflects the phenotype of type A deficient mice, but apparently has a slightly accelerated mortality [44]. Since type $B$ patients do not prosper from cPMP substitution and subsequent metabolites such as molybdopterin or MoCo itself are highly instable, the gene therapy approach described above could be reemployed and explored further using these animals.

\section{Clinical Studies}

The first intravenous cPMP substitution of a type A MoCodeficient patient with MOCS1 mutations convincingly showed a normalization of all biochemical parameters [45]. Although a reversal of already apparent neurological damage could not be expected, further neurodegeneration was stopped. In a subsequent study cPMP treatment of a type A patient was started $4 \mathrm{~h}$ after birth, which resulted in a complete suppression and even reversal of symptoms typical for MoCo deficiency [46]. A prospective cohort study with a total of 16 patients confirmed that cPMP substitution is most effective in type A patients if started before onset of symptoms, but is ineffective in type $B$ patients with pathogenic MOCS2 mutations [47].

\section{Conclusion}

Isolated SUOX deficiency and the three known types of combined MoCo deficiency all result in seizures refractory to common treatment regimen and elevated sulfite levels in the urine. Therefore, urinary sulfite measurement by dipstick analysis is strongly recommended in all unsolved cases of neonatal persistent seizures. Additionally, lowered uric acid is an indicator for the combined MoCo deficiency and a test of this parameter is often included in routine metabolic screening. Additionally, it might be worthwhile to think about the inclusion of the above described genes in genetic screens-especially in the light of ever cheaper whole genome analysis. This would also result in an accelerated pinpointing of the exact type of the disease, which to date is the critical factor in the decision for treatment options.

\section{References}

1. Johnson JL, Coyne KE, Garrett RM, Zabot MT, Dorche C et al. (2002) Isolated sulfite oxidase deficiency: identification of 12 novel SUOX mutations in 10 patients. Hum Mutat 20: 74

2. Reiss J, Hahnewald R (2011) Molybdenum cofactor deficiency: Mutations in GPHN, MOCS1, and MOCS2. Hum Mutat 32: 10-18.

3. Pateman JA, Cove DJ, Rever BM, Roberts DB (1964) A Common Co-Factor for Nitrate Reductase and Xanthine Dehydrogenase Which Also Regulates the Synthesis of Nitrate Reductase. Nature 201: 58-60.

4. Cohen HJ, Fridovich I, Rajagopalan KV (1971) Hepatic sulfite oxidase. A functional role for molybdenum. J Biol Chem 246: 374-382.

5. Schwarz G, Mendel RR, Ribbe MW (2009)Molybdenum cofactors, enzymes and pathways. Nature 460: 839-847.

6. Holder JL Jr, Agadi S, Reese W, Rehder C, Quach MM (2014) Infantile spasms and hyperekplexia associated with isolated sulfite oxidase deficiency. JAMA Neurology 71: 782-784.

7. Ichida K, Amaya Y, Okamoto K, Nishino T (2012)Mutations associated with functional disorder of xanthine oxidoreductase and hereditary xanthinuria in humans. Int J Mol Sci 13: 15475-15495.

8. Vorbach C, Scriven A, Capecchi MR (2002)The housekeeping gene xanthine oxidoreductase is necessary for milk fat droplet enveloping and secretion: gene sharing in the lactating mammary gland. Genes Dev 16: 3223-3235.

9. Jeong J, Lisinski I, Kadegowda AK, Shin H, Wooding FB, et al. (2013) A test of current models for the mechanism of milk-lipid droplet secretion. Traffic 14: 974-986.

10. McManaman JL, Bain DL (2002) Structural and conformational analysis of the oxidase to dehydrogenase conversion of xanthine oxidoreductase. J Biol Chem 277: 21261-21268.

11. Fromer M, Pocklington AJ, Kavanagh DH, Williams HJ, Dwyer S, et al. (2014) De novo mutations in schizophrenia implicate synaptic networks. Nature 506: 179-84.

12. Havemeyer A, Bittner F, Wollers S, Mendel R, Kunze T (2006) Identification of the missing component in the mitochondrial benzamidoxime prodrug-converting system as a novel molybdenum enzyme. J Biol Chem 281: 34796-34802.

13. Ott G, Reichmann D, Boerger C, Cascorbi I, Bittner F, et al. (2014) Functional characterization of protein variants encoded by nonsynonymous single nucleotide polymorphisms in MARC1 and MARC2 in healthy Caucasians. Drug Metab Dispos 42: 718-725.

14. Plitzko B, Ott G, Reichmann D, Henderson CJ, Wolf CR, et al. (2013) The involvement of mitochondrial amidoxime reducing components 1 and 2 and mitochondrial cytochrome b5 in N-reductive metabolism in human cells. J Biol Chem 288: 20228-20237.

15. Reiss J, Cohen N, Dorche C, Mandel H, Mendel RR, et al. (1998) Mutations in a polycistronic nuclear gene associated with molybdenum cofactor deficiency. Nat Genet 20: 51-53.

16. Rajagopalan KV, Johnson JL (1992) The pterin molybdenum cofactors. J Biol Chem 267: 10199-10202

17. Johnson JL, Wuebbens MM, Mandell R, Shih VE (1989) Molybdenum cofactor biosynthesis in humans. Identification of two complementation groups of cofactor-deficient patients and preliminary characterization of a diffusible molybdopterin precursor. J Clin Invest 83: 897-903.

18. Macaya A, Brunso L, Fernandez-Castillo N, Arranz JA, Ginjaar HB, et al. (2005) Molybdenum cofactor deficiency presenting as neonatal hyperekplexia: a clinical, biochemical and genetic study. Neuropediatrics 36: 389-394.

19. Leimkuhler S, Freuer A, Araujo JA, Rajagopalan KV, Mendel RR (2003) Mechanistic studies of human molybdopterin synthase reaction and characterization of mutants identified in group B patients of molybdenum cofactor deficiency. J Biol Chem 278: 26127-26134.

20. Johnson JL, Hainline BE, Rajagopalan KV, Arison BH (1984) The pterin component of the molybdenum cofactor. Structural characterization of two fluorescent derivatives. J Biol Chem 259: 5414-5422.

21. Vaughn LS, Snee B, Patel RC (2014)Inhibition of PKR protects against tunicamycin-induced apoptosis in neuroblastoma cells. Gene 536: 90-96.

22. Suganuma T, Swanson SK, Florens L, Washburn MP, Workman JL (2016) Moco biosynthesis and the ATAC acetyltransferase engage translation initiation by inhibiting latent PKR activity. J Mol Cell Biol 8: 44-50.

23. Matthies A, Rajagopalan KV, Mendel RR, Leimkuhler S (2004) Evidence for the physiological role of a rhodanese-like protein for the biosynthesis of the molybdenum cofactor in humans. Proc Natl Acad Sci U S A 101: 5946-5951.

24. Chowdhury MM, Dosche C, Lohmannsroben HG, Leimkuhler S (2012) Dual role of the molybdenum cofactor biosynthesis protein MOCS3 in tRNA thiolation and molybdenum cofactor biosynthesis in humans. J Biol Chem 287 17297-17307.

25. Kirsch J, Wolters I, Triller A, Betz H (1993) Gephyrin antisense oligonucleotides prevent glycine receptor clustering in spinal neurons. Nature 366: 745-748.

26. Kamdar KP, Shelton ME, Finnerty V (1994) The Drosophila molybdenum cofactor gene cinnamon is homologous to three Escherichia coli cofactor proteins and to the rat protein gephyrin. Genetics 137: 791-801.

27. Stallmeyer B, Nerlich A, Schiemann J, Brinkmann H, Mendel RR (1995) Molybdenum co-factor biosynthesis: the Arabidopsis thaliana cDNA cnx1 encodes a multifunctional two-domain protein homologous to a mammalian neuroprotein, the insect protein Cinnamon and three Escherichia coli proteins. Plant J 8: 751-62.

28. Feng G, Tintrup H, Kirsch J, Nichol MC, Kuhse J, et al. (1998) Dual requirement for gephyrin in glycine receptor clustering and molybdoenzyme activity. Science 282: $1321-1324$

29. Reiss J, Gross-Hardt S, Christensen E, Schmidt P, Mendel RR (2001) A mutation in the gene for the neurotransmitter receptor-clustering protein gephyrin causes a novel form of molybdenum cofactor deficiency. Am J Hum Genet 68: 208-213.

30. Grosskreutz Y, Betz H, Kneussel M (2003) Rescue of molybdenum cofactor 
biosynthesis in gephyrin-deficient mice by a $\mathrm{Cnx} 1$ transgene. Biochem Biophys Res Commun 30: 450-455.

31. Reiss J, Lenz U, Aquaviva-Bourdain C, Joriot-Chekaf S, Mention-Mulliez K, et al. (2011) A GPHN point mutation leading to molybdenum cofactor deficiency. Clin Genet 80: 598-599.

32. Rees MI, Harvey K, Ward H, White JH, Evans L, et al. (2003) Isoform heterogeneity of the human gephyrin gene (GPHN), binding domains to the glycine receptor, and mutation analysis in hyperekplexia. J Biol Chem 278: 24688-24696.

33. Smolinsky B, Eichler SA, Buchmeier S, Meier JC, Schwarz G (2008) Splicespecific functions of gephyrin in molybdenum cofactor biosynthesis. J Biol Chem 283: $17370-17379$

34. Forstera B, Belaidi AA, Juttner R, Bernert C, Tsokos M, et al. (2010) Irregular RNA splicing curtails postsynaptic gephyrin in the cornu ammonis of patients with epilepsy. Brain 133: 3778-3794.

35. Lionel AC, Vaags AK, Sato D, Gazzellone MJ, Mitchell EB, et al. (2013) Rare exonic deletions implicate the synaptic organizer Gephyrin (GPHN) in risk for autism, schizophrenia and seizures. Hum Mol Genet 22: 2055-2066.

36. Reiter S, Simmonds HA, Zollner N, Braun SL, Knedel M (1990) Demonstration of a combined deficiency of xanthine oxidase and aldehyde oxidase in xanthinuric patients not forming oxipurinol. Clin Chim Acta 187: 221-234

37. Zhou Y, Zhang X, Ding R, Li Z, Hong Q, et al. (2015) Using Next-Generation Sequencing to Identify a Mutation in Human MCSU that is Responsible for Type II Xanthinuria. Cell Physiol Biochem 35: 2412-2421.

38. Feron F, Gepner B, Lacassagne E, Stephan D, Mesnage B, et al. (2002) Olfactory stem cells reveal MOCOS as a new player in autism spectrum disorders. Mol Psychiatry.

39. Lee HJ, Adham IM, Schwarz G, Kneussel M, Sass JO, et al. (2002) Molybdenum cofactor-deficient mice resemble the phenotype of human patients. Hum Mol Genet 11: 3309-3317.

40. Schwarz G, Santamaria-Araujo JA, Wolf S, Lee HJ, Adham IM, et al. (2004) Rescue of lethal molybdenum cofactor deficiency by a biosynthetic precursor from Escherichia coli. Hum Mol Genet 13: 1249-1255.

41. Kugler S, Hahnewald R, Garrido M, Reiss J (2007) Long-term rescue of a lethal inherited disease by adeno-associated virus-mediated gene transfer in a mouse model of molybdenum-cofactor deficiency. Am J Hum Gene 80: 291297.

42. Hahnewald R, Wegner W, Reiss J (2009) AAV-mediated gene therapy for metabolic diseases: dosage and reapplication studies in the molybdenum cofactor deficiency model. Genet Vaccines Ther 7: 9.

43. Chandler RJ, LaFave MC, Varshney GK, Trivedi NS, Carrillo-Carrasco N, et al. (2015) Vector design influences hepatic genotoxicity after adeno-associated virus gene therapy. J Clin Invest 125: 870-880.

44. Jakubiczka-Smorag J, Santamaria-Araujo JA, Metz I, Kumar A, Hakroush S, et al. (2016) Mouse model for molybdenum cofactor deficiency type B recapitulates the phenotype observed in molybdenum cofactor deficient patients. Hum Genet

45. Veldman A, Santamaria-Araujo JA, Sollazzo S, Pitt J, Gianello R, et al. (2010) Successful treatment of molybdenum cofactor deficiency type A with cPMP. Pediatrics 125: e1249-e1254.

46. Hitzert MM, Bos AF, Bergman KA, Veldman A, Schwarz G, et al. (2012) Favorable outcome in a newborn with molybdenum cofactor type A deficiency treated with cPMP. Pediatrics 130: e1005-e1010.

47. Schwahn BC, Van Spronsen FJ, Belaidi AA, Bowhay S, Christodoulou J, et al. (2015) Efficacy and safety of cyclic pyranopterin monophosphate substitution in severe molybdenum cofactor deficiency type $\mathrm{A}$ : a prospective cohort study. Lancet 386: 1955-1963.

48. Rocha S, Ferreira AC, Dias Al, Vieira JP, Sequeira S (2014) Sulfite oxidase deficiency - an unusual late and mild presentation. Brain Dev 36: 176-179.

49. Seidahmed MZ, Alyamani EA, Rashed MS, Saadallah AA, Abdelbasit OB, et al. (2005) Total truncation of the molybdopterin/dimerization domains of SUOX protein in an Arab family with isolated sulfite oxidase deficiency. Am J Med Genet A 136: 205-209.

50. Rupar CA, Gillett J, Gordon BA, Ramsay DA, Johnson JL, et al. (1996) Isolated sulfite oxidase deficiency. Neuropediatrics 27: 299-304.
51. Edwards MC, Johnson JL, Marriage B, Graf TN, Coyne KE, et al. (1999) Isolated sulfite oxidase deficiency: review of two cases in one family. Ophthalmology 106: $1957-1961$

52. Kisker C, Schindelin H, Pacheco A, Wehbi WA, Garrett RM, et al. (1997) Molecular basis of sulfite oxidase deficiency from the structure of sulfite oxidase. Cell 91: 973-983.

53. Salih MA, Bosley TM, Alorainy IA, Sabry MA, Rashed MS, et al. (2013) Preimplantation genetic diagnosis in isolated sulfite oxidase deficiency. Can J Neurol Sci 40: 109-112.

54. Tan WH, Eichler FS, Hoda S, Lee MS, Baris H, et al. (2005) Isolated sulfite oxidase deficiency: a case report with a novel mutation and review of the literature. Pediatrics 116: 757-766.

55. Chen LW, Tsai YS, Huang CC (2014) Prenatal multicystic encephalopathy in isolated sulfite oxidase deficiency with a novel mutaion. Pediatr Neurol 51: 181182.

56. Reiss J, Christensen E, Kurlemann G, Zabot MT, Dorche C (1998) Genomic structure and mutational spectrum of the bicistronic MOCS1 gene defective in molybdenum cofactor deficiency type A. Human Genet 103: 639-644.

57. Leimkuhler S, Charcosset M, Latour P, Dorche C, Kleppe S, et al. (2005) Ten novel mutations in the molybdenum cofactor genes MOCS1 and MOCS2 and in vitro characterization of a MOCS2 mutation that abolishes the binding ability of molybdopterin synthase. Human Genet 117: 565-570.

58. Bayram E, Topcu Y, Karakaya P, Yis U, Cakmakci H, et al. (2013) Molybdenum cofactor deficiency: review of 12 cases (MoCD and review). Eur J Paediatr Neurol 17: 1-6.

59. Reiss J, Johnson JL (2003) Mutations in the molybdenum cofactor biosynthetic genes MOCS1, MOCS2, and GEPH. Hum Mutat 21: 569-576.

60. Arenas M, Fairbanks LD, Vijayakumar K, Carr L, Escuredo E (2009) An unusual genetic variant in the MOCS1 gene leads to complete missplicing of an alternatively spliced exon in a patient with molybdenum cofactor deficiency. $\mathrm{J}$ Inherit Metab Dis 32: 560-569.

61. Hahnewald R, Leimkuhler S, Vilaseca A, Acquaviva-Bourdain C, Lenz U (2006) A novel MOCS2 mutation reveals coordinated expression of the small and large subunit of molybdopterin synthase. Mol Genet Metab 89: 210-213.

62. Reiss J, Dorche C, Stallmeyer B, Mendel RR, Cohen N (1999) Human molybdopterin synthase gene: genomic structure and mutations in molybdenum cofactor deficiency type B. Am J Hum Genet 64: 706-711.

63. Johnson JL, Coyne KE, Rajagopalan KV, Van Hove JL, Mackay M, et al. (2001) Molybdopterin synthase mutations in a mild case of molybdenum cofactor deficiency. Am J Med Genet 104: 169-173.

64. Per H, Gumus H, Ichida K, Caglayan O, Kumandas S (2007) Molybdenum cofactor deficiency: clinical features in a Turkish patient. Brain Dev 29: 365-368. 